\title{
Pediatric cardiac care in India: current status and the way forward
}

\author{
Anita Saxena*,1 \\ ${ }^{1}$ Department of Cardiology, All India Institute of Medical Sciences, New Delhi 110029, India \\ * Author for correspondence: Tel.: +91 11 26594861; Fax: +91 11 26588663; anitasaxena@hotmail.com
}
"Due to high birth rates in India, it is expected that approximately 150,000-200,000 children are born with CHD in India every year"

First draft submitted: 4 September 2017; Accepted for publication: 4 October 2017; Published online: 23 November 2017

Keywords: cardiac care $\bullet$ congenital heart disease $\bullet$ India $\bullet$ intervention $\bullet$ neonates $\bullet$ pediatric cardiac centers

Congenital heart disease (CHD) is one of the most common types of birth defects. Out of 100 children born around the world, one is expected to have CHD [1] and newborn survival rates depend on where in the world the baby is born. If access to screening, early diagnosis and treatment is available, the baby has a $95 \%$ chance of survival with good long-term outcome [2]. Such advanced care is practically unavailable to over $90 \%$ of babies born in developing countries, including India [3]. While one cardiac center caters to a population of approximately 120,000 in North America, in Asia, a population of 16 million people is served by one center [4]. In Africa, this ratio is one center per 33 million people [4]. Similarly, the number of cardiac surgeons per person is considerably better in North America and Europe (one cardiac surgeon per 3.5 million people) as compared with Asia (one cardiac surgeon per 25 million) [5]. These figures indicate the number of children born with CHD in Asia and Africa that have no or minimal access to healthcare, which ultimately results in a much higher child mortality rate compared with the rest of the world.

\section{The current scenario}

Hospital-based studies have shown that the prevalence of CHD in India does not seem to be much different from the worldwide prevalence [6,7]. Due to high birth rates in India, it is expected that approximately $150,000-200,000$ children are born with CHD in India every year [8]. Of these, approximately a third to a quarter $(\sim 50,000)$ would need early intervention to survive the first year of life [9]. These estimates are based on regional hospital-based data and the actual numbers may be higher considering the high rates of maternal infections during pregnancy and a significant percentage of unsupervised home deliveries where critical CHD may escape detection. The magnitude of the problem is further compounded by a large pool of older infants and children who may have survived, despite no intervention.

Since the majority of children are not intervened, the mortality and morbidity due to CHD is expected to be very high in India. According to a publication in 2005 , less than $5 \%$ of babies born with critical CHD actually undergo cardiac surgery or any other form of intervention in India [8]. Following this publication however, the total country-wide number of infant open heart procedures almost doubled over the next 5 years [10]. This total number may have also increased even further since another 10-12 centers have been setup in the last 5 years. Most centers caring for CHD patients are however in the private sector and may therefore not be affordable for the majority of the Indian population. Unfortunately, the number of government-aided centers and public hospitals has not expanded much in recent years. As for other diseases, members of the poorer population rely primarily on government aided programs. Public hospitals are faced with a large number of patients and have waiting lists ranging from months to years, especially as the emergency cases get priority over stable patients. Children undergoing surgery are often in advanced stages of heart failure, have severe cyanosis, pulmonary vascular disease and associated malnutrition [11]. The results of intervention in such settings may have long term sequelae. 
The geographical distribution of these centers is also very uneven and a number of centers have been established over the last 15 years or so in the southern states of India. These states are considered to be economically better off, with higher domestic products and have better literacy levels. Families in these states therefore have better affordability and awareness about CHD. Some of the most populous states of India (with the highest birth rates and lower domestic product) in central and eastern parts do not have even one center that can provide optimal care for neonates and infants born with CHD. A clear disparity exists between rural and urban and, between poor and the affluent patients. Therefore, a vast majority of children born in India with CHD have no access to affordable treatment. Rapid population growth, lack of healthcare funding, competing priorities, inefficient and inadequately equipped infrastructure and shortage of trained staff are some of the major roadblocks to cardiac care of children with CHD.

The diagnosis of CHD is often delayed, which may partly be due to occurrence of home births in unsupervised settings. In recent years, the rate of hospital deliveries has significantly increased to over $70 \%$ due to several incentive driven schemes by the Government of India. Predischarge screening of newborns by pulse oximetry is very infrequently practiced, however, especially in rural and semi-urban centers. Neonates with ductus-dependent CHD often go home undiagnosed. The rates of antenatal diagnosis of CHD appear to be very low despite ultrasound examination during pregnancy in many women (exact data unavailable). This is in contrast to a prenatal diagnosis rate of $63.8 \%$ [12]. Significant delay often occurs between diagnosis and referral to a cardiac center $[8,13]$. This stems from limited knowledge about available treatment facilities for CHD among the primary care givers (physicians/pediatricians). Many health professionals are unaware of the advances made in the treatment of newborns with CHD and parents are counseled against interventions for apprehension of poor long-term outcome. Most of the health staff, including physicians, nurses and other health workers lack training in recognizing CHD. Delay in referral results in suboptimal management and poor outcome as complications and comorbidities (such as under nutrition) may have already set in.

After diagnosis of CHD is made, many families find it too expensive to travel long distances and stay in hotels/other places in metropolitan cities with very different local conditions. Congenital heart surgery is expensive and families are expected to pay out of their own pockets, which many families can often ill afford. Insurance companies also do not cover the cost of treatment of CHD in India. Despite the fact that several state government-level programs, microfinance schemes, charitable and philanthropic organizations exist for the benefit of economically weaker sections of the society, awareness about such programs is often very low. Public hospitals, which are fully equipped to provide interventions at a low cost, are very few. A flagship scheme of Government of India (Rashtriya Bal Swasthya Karyakram [RBSK]) was launched in 2013 with a mandate to screen all children, aged 0-18 years for early detection and management of birth defects and other diseases. Under this initiative, comprehensive healthcare is provided for all diagnosed cases. Given the huge volume of cases, it is likely that it will take some time before this scheme makes a significant impact on overall CHD patient care [14].

Unlike in the west, where infectious disease is virtually nonexistent, India is facing a dual burden of diseases, both infectious and noncommunicable diseases, resulting in significant morbidity and mortality. Total investment on healthcare by the government is $1.4 \%$ of the gross domestic product and is one of the lowest when compared with several other countries, including many developing nations [15]. Of the total budget, priority is given to infectious diseases such as malaria, tuberculosis and HIV/AIDS, and malnutrition. However, the policy makers and others in the government are taking note of pediatric health and in the future, we may see increased spending which would also help the cause of CHD.

Finally, health-seeking behavior and prevailing religious and sociocultural practices also contribute to lack of optimal care for children with CHD. In a study from a referral tertiary care center, girls were less likely to undergo cardiac surgery for $\mathrm{CHD}$ than boys [16]. This could be due to the perception that a scar on the chest may adversely affect the chances of a girl's marriage. Children who have undergone an intervention for CHD are often lost to follow-up, despite the fact that many of these would require long-term follow-up, with further interventions in some. This is especially true for illiterate and poor families.

\section{The way forward?}

So, what can be done to improve the current situation? Going by the last 20 years' experience, significant strides have been made in trying to provide better healthcare for these children. Since India is a very large country with limited resources, however, it is surely a difficult task. Health is a state-level matter and the various states of India differ vastly in their economy, literacy levels, population, language, cultural beliefs and human development index. 
This regional diversity makes the task even more difficult as a 'one-size-fits-all' approach is not tenable. The limited resources need to be effectively utilized. General measures include lowering birth rates, immunization against rubella and improving women's health and nutrition, etc. Specific national programs tailored to the needs of children with heart disease are resource intensive and may not be sustainable in the long run. A comprehensive program which caters to the well-being of children in general, and incorporates a number of other common disorders is more likely to succeed. The RBSK scheme is working on this principle, although it may be too early to make any comment on its impact. Sensitizing the primary care givers about CHD through periodic education programs is of utmost importance, if an early diagnosis is to be achieved. Screening newborns with pulse oximetry to diagnose critical CHD has been found to be useful in several studies in the past, including a study from India [17], and should become a part of newborn care. Use of telemedicine and internet applications including transfer of echocardiographic data can also reduce delays in diagnosis.

Specific measures include establishing more centers that can cater to the needs of neonates, infants and children with CHD. This is a challenging task due to the large investments required in terms of sophisticated technology, infrastructure and trained personnel. Such centers should be able to attract a trained and motivated team of health professionals including cardiologists, surgeons, intensivists and other cardiovascular specialists. Importantly, these centers should be more equally geographically distributed, preferably with at least one center in each state unit, so that families do not have to travel such long distances to new cities with different local environments and languages. Each such state level center will have enough patient load considering the large population of most states of India. In fact, some of the more populous states may well require two or three cardiac centers. It would be prudent to establish government aided centers that provide affordable care, since a large number of patient families belong to middle and lower strata on socioeconomic scale.

As the remuneration differential for staff employed in the private and public health facilities is wide, the government should consider providing incentives to employ experienced, qualified personnel with vision and leadership qualities, when starting a new center. 'Hand holding' of new recruits by senior staff/expatriates on short term deputation from established cardiac centers may also be helpful in the initial phases. In-country, structured training programs (such as in Brazil) for cardiologists, surgeons, intensivists and anesthesiologists are necessary for sustainability and growth of this subspecialty. China developed in-country training programs which have been shown to be feasible and cost-effective [18]. In the last 5 years, a foundation has been built in India and a limited number of good quality training programs have begun to emerge. This number is increasing, albeit slowly. In addition, the internet and telemedicine are being successfully used to transfer knowledge and skills [19].

Cost containment is necessary for cardiac surgery to be affordable. Encouraging home grown technology, resterilizing and reusing consumables and exclusion of the 'middle man' for importing equipment and consumables, cuts down cost significantly. Incorporating research into a program is very important and helps in its sustainability.

Standalone pediatric cardiac hospitals (or free standing children cardiac centers) tend to be very resource intensive. Piggybacking pediatric cardiac surgical programs on a successful ongoing adult cardiac program is practiced in many centers as it optimizes resource utilization. The cardiac catheterization lab, operating rooms and other lab services are shared for both pediatric and adult patients. In such 'adult-program-first' models, the pediatric cardiac program is gradually expanded. Relatively more simple surgeries are performed initially. Later, with dedicated staff and equipment, more demanding surgeries are performed, including those on neonates and small infants. Since the burden of CHD is enormous, preference may be given to patients with $\mathrm{CHD}$ which are 'one-time fixes' over complex CHD cases which require multistage, often palliative surgeries with suboptimal long-term survival. The denial of cardiac surgery to children with complex CHD (e.g., heterotaxy syndrome) and to those associated with significant extra cardiac malformations is for efficient resource utilization in a resource strapped setting. Such decisions can be challenged and are best taken in consultation with parents as many would want to do everything possible for their children. Finally, if the centers are to excel, a constant evaluation of their performance is mandatory. All efforts should be made to follow postintervention patients meticulously. Collection of outcome data to assess the quality of program is very important for self-sustainability and this data should be for early, mid-term and long-term outcomes.

\section{Conclusion}

A significant amount of progress has been made in India as far as management of children with CHD is concerned and one remains optimistic for future growth and progress. Further improvement must be made for early diagnosis and the creation of a network so that patients can be referred to a treatment facility which is locally available. 
India is a vast country with a huge population and networking is a daunting task. However, to make sure that the cardiac care is not provided in silos with accompanying wastage of limited resources, such networks would be very important. Interaction with pediatricians and other front-line health staff is necessary if we want to improve the overall outlook for children with CHD. Potential solutions to improve access to cardiac care must keep in mind the local social, economic and political systems for each region. Advocacy with health policy makers to make them aware of the extent of the problem is very important. This will enable allocation of more resources and their optimal utilization toward care of children with CHD, at primary, secondary and tertiary levels. All of these efforts must be complemented with research, which is locally relevant.

\section{Financial \& competing interests disclosure}

The author has no relevant affiliations or financial involvement with any organization or entity with a financial interest in or financial conflict with the subject matter or materials discussed in the manuscript. This includes employment, consultancies, honoraria, stock ownership or options, expert testimony, grants or patents received or pending, or royalties.

No writing assistance was utilized in the production of this manuscript.

\section{References}

1. Hoffman JL, Kaplan S. The incidence of congenital heart disease. J. Am. Coll. Cardiol. 39(12), 1890-1900 (2002).

2. Warnes CA. The adult with congenital heart disease: born to be bad. J. Am. Coll. Cardiol. 46(1), 1-8 (2005).

3. Tchervenkov C, Jacobs J, Bernier P et al. The improvement of care for paediatric and congenital cardiac disease across the World: a challenge for the World Society for Pediatric and Congenital Heart Surgery. Cardiol. Young. 18(Suppl. 2), 63-69 (2008).

4. Pezzella T. Worldwide maldistribution of access to cardiac surgery. Letter to the editor. J. Thorac. Cardiovasc. Surg. 123(5), 1016 (2002).

5. Hoffman JI. The global burden of congenital heart disease. Cardiovasc. J. Afr. 24(4), 141-145 (2013).

6. Saxena A, Mehta A, Sharma M et al. Birth prevalence of congenital heart disease: a cross-sectional observational study from North India. Ann. Pediatr. Card. 9(3), 205-209 (2016).

7. Vaidyanathan B, Sathish G, Mohanan ST, Sundaram KR, Warrier KK, Kumar RK. Clinical screening for congenital heart disease at birth: a prospective study in a community hospital in Kerala. Ind. Pediatr. 48(1), 25-30 (2011).

8. Saxena A. Congenital heart disease in India: a status report. Ind. J. Ped. 72(7), 595-598 (2005).

9. Kothari SS. Pediatric cardiac care for the economically disadvantaged in India: problems and prospects. Ann. Pediatr. Cardiol. 2(1), 95-8 (2009).

10. Kumar RK. The nuts and bolts of pediatric cardiac care for the economically challenged. Ann. Pediatr. Cardiol. 2(1), 99-101 (2009).

11. Liu J. Challenges and progress of the pediatric cardiac surgery in Shanghai Children's Medical Center: a 25-year solid collaboration with Project HOPE. Semin. Thorac. Cardiovasc. Surg. Pediatr. Card. Surg. Annu. 12-18 (2009).

12. Liberman RF, Getz KD, Lin AE et al. Delayed diagnosis of critical congenital heart defects: trends and associated factors. Pediatrics. 134(2), e373-e381 (2014).

13. Rashid U, Qureshi AU, Hyder SN, Sadiq M. Pattern of congenital heart disease in a developing country tertiary care center: Factors associated with delayed diagnosis. Ann. Pediatr. Card. 9(3), 210-215 (2016)

14. Rashtriya Bal Swasthya Karyakram (RBSK). Child Health Screening and Early Intervention Services under NRHM, Ministry of Health \& Family Welfare, New Delhi, Government of India. http://rbsk.gov.in

15. The World Bank. Health expenditure, public (\% of GDP). http://data.worldbank.org/indicator/SH.XPD.PUBL.ZS

16. Ramakrishnan S, Khera R, Jain S et al. Gender differences in the utilisation of surgery for congenital heart disease in India. Heart $97(23)$, 1920-1925 (2011).

17. Saxena A, Mehta A, Ramakrishnan S et al. Pulse oximetry as a screening tool for detecting major congenital heart defects in Indian newborns. Arch. Dis. Child. Fetal. Neonatal. Ed. 100(5), F416-F421 (2015).

18. Pezzella AT. Cardiothoracic surgery residency program in Shanghai, China. Ann. Afr. Chir. Thor. Cardiovasc. 4, 81-99 (2009).

19. Nguyen N, Leon-Wyss J, Iyer KS, Pezzella AT. Paediatric cardiac surgery in low-income and middle-income countries: a continuing challenge. Arch. Dis. Child. 100(12), 1156-1159 (2015). 